\title{
Three-dimensional human skin models to understand Staphylococcus aureus skin colonization and infection
}

\author{
${ }^{1}$ Microbiology and Immunology, Stanford University School of Medicine, Stanford, CA, USA \\ 2 Program in Epithelial Biology, Stanford University School of Medicine, Stanford, CA, USA \\ ${ }^{3}$ Novartis Vaccines, Siena, Italy \\ ${ }^{4}$ Pediatrics, Stanford University School of Medicine, Stanford, CA, USA
}

Lauren Popov' ${ }^{1}$, Joanna Kovalski ${ }^{2}$, Guido Grandi ${ }^{3}$, Fabio Bagnoli ${ }^{3}$ and Manuel R. Amieva ${ }^{1,4}$ *

Edited by:

Sylvie Bertholet, Novartis Vaccines and Diagnostics, Italy

Reviewed by:

Birgit Strobl, University of Veterinary Medicine Vienna, Austria

Ren Sun, University of California Los Angeles, USA

\section{*Correspondence.}

Manuel R. Amieva, Microbiology and Immunology, Stanford University School of Medicine, 299 Campus Drive, Stanford, CA 94305, USA e-mail: amieva@stanford.edu
Staphylococcus aureus is both a major bacterial pathogen as well as a common member of the human skin microbiota. Due to its widespread prevalence as an asymptomatic skin colonizer and its importance as a source of skin and soft tissue infections, an improved understanding of how $S$. aureus attaches to, grows within, and breaches the stratified layers of the epidermis is of critical importance. Three-dimensional organotypic human skin culture models are informative and tractable experimental systems for future investigations of the interactions between $S$. aureus and the multi-faceted skin tissue. We propose that $S$. aureus virulence factors, primarily appreciated for their role in pathogenesis of invasive infections, play alternative roles in promoting asymptomatic bacterial growth within the skin. Experimental manipulations of these cultures will provide insight into the many poorly understood molecular interactions occurring at the interface between $S$. aureus and stratified human skin tissue.

Keywords: Staphylococcus aureus, MRSA, skin, colonization, organ culture
Staphylococcus aureus is simultaneously a pathogen of significant morbidity and mortality and a common member of the skin microbiota. As a major human bacterial pathogen, S. aureus infections cause tens of thousands of deaths and millions of outpatient and emergency room visits in the United States annually (1). Although the disease caused by $S$. aureus infections manifests in a wide range of clinical presentations, the vast majority are skin and soft tissue infections $(2,3)$.

However, in spite of the pathogenesis associated with $S$. aureus, it is also acknowledged to be a typical member of the complex community of microbes living on and within our skin (4, 5). An estimated $20 \%$ of American adults are persistently colonized in the anterior nares with $S$. aureus, and an additional $30 \%$ are intermittently carrying $S$. aureus in the nares $(6,7)$. For neonates and children, the prevalence of $S$. aureus positive skin cultures is thought to be even higher $(8,9)$. Furthermore, evidence from recent prevalence studies in which non-nasal skin sites are surveyed suggests that traditional screening approaches may be underestimating a larger skin colonization burden of $S$. aureus by focusing on one niche, the anterior nares (10-12). Little is known about the transition from the asymptomatic colonization state to an invasive infection, despite the fact that persistently colonized individuals have nearly triple the risk of developing $S$. aureus bacteremia and are most often infected by their own colonizing strains (13-16).

Whether one considers $S$. aureus as an invasive pathogen or from the perspective of its role as a common colonizer, an appreciation of how $S$. aureus interacts with the skin environment is central to its biology. Much remains unknown about how S. aureus persists in the skin over time and what bacterial factors it may use to actively modify the host skin environment to persist in its replicative niche. We propose that three-dimensional (3D) human skin culture models are an informative and tractable experimental system for future investigations of the interactions between $S$. aureus and the multi-faceted skin tissue. In this perspective, we consider the current experimental model systems for studying the $S$. aureus skin interface, and describe advantages of utilizing organotypic $3 \mathrm{D}$ human skin models for future investigations into $S$. aureus biology.

Historically, many of the molecular biology studies into $S$. aureus skin interactions have been done using in vitro infections of keratinocytes cultured as a two-dimensional (2D) monolayer of cells. Such studies have provided insight into many aspects of bacterial attachment and the innate immune response mounted by keratinocytes upon encountering bacteria $(17,18)$. However, the bi-dimensional nature of these assays completely eludes the complex stratification and terminal differentiation process central to how keratinocytes form a multilayered epidermal tissue with barrier functionality. To study determinants of $S$. aureus interaction with a stratified skin tissue (as opposed to isolated keratinocytes), investigators have relied on a variety of animal models. Epicutaneous or superficial epidermal inoculation of $S$. aureus in rodent skin models have proven ineffective for reproducible observations of $S$. aureus growth on skin over extended periods of time (1922). Further, there are considerable differences between human skin and rodent skin in both histology and immunology, which complicate interpretation of data with respect to bacterial localization and replication in the skin. A recently developed murine model of $S$. aureus skin and soft tissue infections uses small allergy test needles coated in bacteria to introduce the inoculum precisely 
and superficially into the outer ear pinna (23). This model has been used to examine the immune response to a superficial $S$. aureus skin infection (23). With this notable exception, nearly all of the existing $S$. aureus animal skin models require severe mechanical disruption of the skin to facilitate bacterial growth, such as the subcutaneous foot pad model, the scalpel wound model, or the subcutaneous skin abscess model (24-27). While these models are extremely useful for studying pathogenesis, they neither facilitate observation of the replicative niche of $S$. aureus within an intact tissue, nor address how the transition of $S$. aureus from an asymptomatic colonization state to a more invasive soft tissue or systemic infection might occur.

Due to the need for a physiologically relevant in vitro model system to dissect the interactions of $S$. aureus with intact human skin, we have modified an existing 3D organotypic human skin tissue model to examine the processes of staphylococcal skin colonization and infection $(28,29)$. An appreciation of the inherent limitations of 2D cultures for understanding skin biology has motivated the development of many tools to study stratified human skin tissue over the past several decades (30-32). Only recently, microbiologists have begun to capitalize on these advancements and utilize 3D organotypic human skin models to examine the specific interactions between the human skin and clinically relevant viral, bacterial, and fungal species $(31,33-36)$.

Established models for studying stratified human skin fall into two main categories, namely ex vivo human skin explant cultures and regenerated $3 \mathrm{D}$ organotypic models derived from primary cells and/or human cell lines. All 3D skin models are relatively labor and time intensive when compared to traditional 2D skin models using keratinocyte-derived cell lines. Ex vivo human skin explants, typically acquired from neonatal foreskin, surgical, or cadaveric tissues, can be maintained in cell culture media directly or on supports in an air-liquid interface and remain viable in culture for up to 2 weeks. Skin explants have the advantage of containing all resident cell types of the epidermis and dermis as well as skin appendages; however, there are limited options for experimental manipulation of host genetics as well as restricted availability of such tissue samples. Organotypic 3D skin models (sometimes referred to as reconstructed skin models) are generally comprised of primary or immortalized human keratinocytes, grown at an air-liquid interface on an extracellular support matrix, which can be seeded with fibroblasts $(32,37,38)$. Other relevant cell types have been incorporated into organotypic skin models including melanocytes, Langerhans cells, as well as endothelial and nervous cells [reviewed in Ref. (30)]. Organotypic 3D stratified human skin cultures comprised of immortalized human cell lines such as the widely studied $\mathrm{HaCaT}$ cell line do not reflect the intrinsic genetic variability of cultures cultivated using primary keratinocytes, leading some to argue that models built using the former cells are more reproducible (32). On the other hand, HaCaT 3D organotypic cultures exhibit differentiation and stratification deficiencies when compared to primary keratinocyte $3 \mathrm{D}$ organotypic skin cultures (39-41).

In the $3 \mathrm{D}$ organotypic human epidermal tissue model we have modified to study $S$. aureus colonization and infection, primary human keratinocytes and fibroblasts are isolated from fresh discarded neonatal foreskin specimens $(28,29)$. Fibroblasts are seeded into pieces of devitalized human dermal tissue derived from cadaveric donors to provide the underlying support matrix. Keratinocytes are then seeded on top of the fibroblast-populated dermis and grow at the air-liquid interface (Figure 1B). After several days of growth, the keratinocytes fully differentiate, generating a basement membrane and all of the stratified epidermal layers, including the outermost squames of the stratum corneum (Figure 1A). The resulting 3D human organotypic tissues are composed entirely of human protein and cells, and unlike murine skin these human organotypic tissues recapitulate the thickness and most of the cellular architecture of the human epidermis and underlying dermis. A limitation of this model is the high genetic variability of skin cultures due to the use of primary cells from heterogeneous donors. Another feature of the model that needs to be improved in the future is the absence of cell types other than keratinocytes and fibroblasts, and skin appendages such as hair follicles and apocrine and eccrine sweat glands.

Epicutaneous infections of these 3D human skin cultures with $S$. aureus USA300 constitutively expressing GFP allow us to follow the bacteria during the colonization process over time. Overnight colonies of bacterial cultures grown on agar plates are re-suspended in Hanks buffer, and the inoculum is applied to the air interface of the skin culture using a pipette tip. At various times after infection, the skin cultures are harvested into paraformaldehyde fixative and further processed for cryosectioning. Using confocal microscopy to generate $3 \mathrm{D}$ images of infected skin tissue, we can examine the bacterial skin interface both from a "top-down" view (Figures 2B,D) as well as by looking at crosssectional slices (Figure 2C). We have tested whether the bacteria are capable of growing on the regenerated human epidermis without exogenous addition of nutrients or media. By starting with a very small inoculum so that mainly single bacteria adhere to the corneocyte surface, we can follow the fate of the microbes over time and determine whether they grow and their preferential replication niche. By 2 days post-infection, the bacteria have expanded to form microcolonies localized at different levels within the stratum corneum of the epidermis (Figure 2, compare Figures 2A,B to later stages of growth in Figures 2C,D). Experiments done with antibiotics added to the basal media reveal this bacterial growth depends on direct interactions with the keratinocytes and not from contact with the cell culture media in the basolateral compartment of the skin cultures (data not shown).

This model system will allow us to query multiple poorly understood aspects of the interactions between $S$. aureus and skin tissue. For example, we can more precisely identify the replicative niche of $S$. aureus within the skin. Does a deeper, quiescent reservoir population of bacteria seed a more rapidly expanding population of surface associated bacteria in the stratum corneum? In addition to examining the location of bacterial attachment and growth during colonization, we can use this experimental system to observe a more pathogenic bacterial invasion of the epidermis. By modulating the maturity of the skin cultures at the time of infection, we can create conditions where bacteria are interacting with nucleated keratinocytes localized to more basal layers of the epidermis.

Unlike human or porcine skin explant models, a key advantage of an in vitro 3D epidermal organotypic system is that it allows the study of skin colonization and infection processes by 

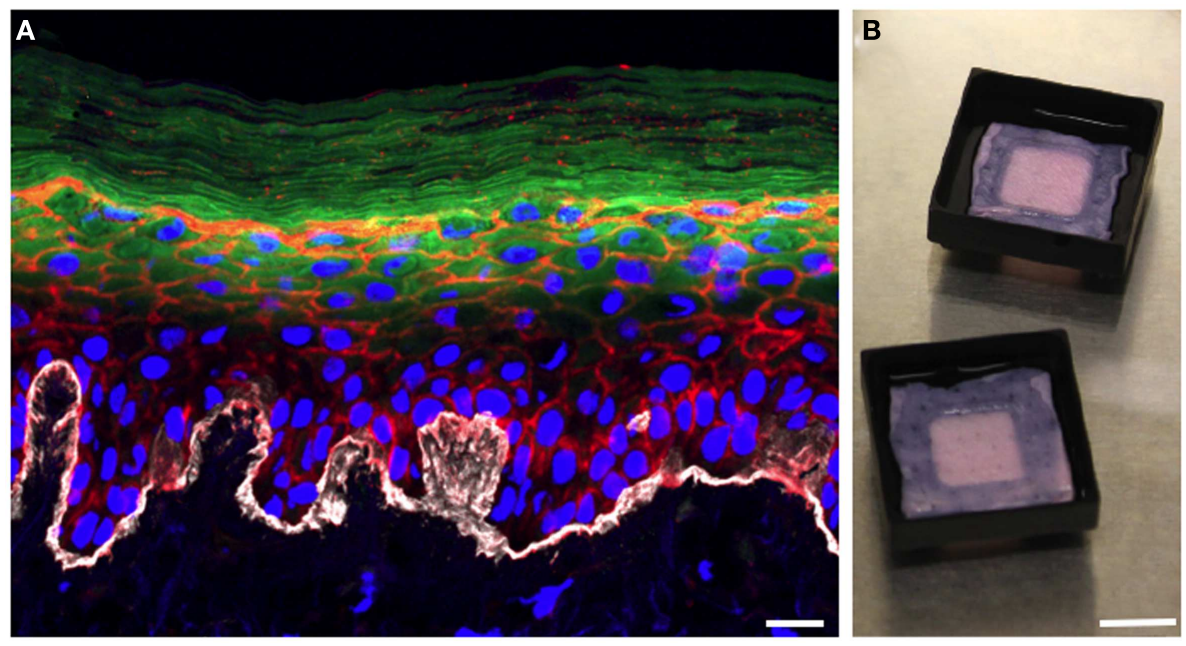

FIGURE 1 |Three-dimensional organotypic human epidermal tissues recapitulate the stratified structure of the epidermis. (A) Cross-sectional view of a fully differentiated 3D human organotypic epidermal tissue. Collagen VII (white) comprising the basement membrane is visible at the interface between the dermis and epidermis. Nuclei of keratinocytes and fibroblasts are blue, filamentous actin is red, and loricrin (green) localizes to the granular layer and the squames of the stratum corneum. Scale bar is $10 \mu \mathrm{m}$. (B) Top-down macroscopic view of the 3D organotypic human epidermal tissue system. Pieces of devitalized human dermis are seeded with primary human keratinocytes and fibroblasts. Tissue culture support trays raise the organotypic human epidermal tissue and promote keratinocyte differentiation by facilitating growth at the air-liquid interface. Scale bar is $1 \mathrm{~cm}$. experimentally controlling both the skin tissue as well as the bacteria (42-44). In this model, the contribution of specific host keratinocyte factors to generate an effective epidermal barrier or to provide critical innate immune responses can be examined. Human keratinocytes treated with RNAi against a gene of interest prior to seeding the dermis generate skin tissue, which is stably knocked-down for a particular gene of interest $(28,29)$. By then infecting these "custom knocked-down" skin tissues, in the future we can examine how tissues deficient in a particular structural or innate immune product may alter the replicative niche of $S$. aureus. Specifically, this approach could prove useful to assess the role of the host protein filaggrin in staphylococcal infections of skin cultures (45). A better understanding of staphylococcal interactions with filaggrin-depleted skin is relevant due to the contribution of filaggrin to the pathology of atopic dermatitis, a dermatological condition, which is known to enhance $S$. aureus skin colonization as well as pre-dispose patients to staphylococcal skin infections (46-48). Indeed, 3D organotypic human skin cultures depleted for filaggrin using siRNA technology have been reported in the dermatological literature (49).

In addition to experimentally manipulating the host side of the system, we can query the impact of specific bacterial virulence factors in promoting growth and invasion processes. The role played by $S$. aureus virulence determinants in skin persistence is an area ripe for inquiry. A handful of staphylococcal virulence factors have known host targets within the skin, most notably the exfoliative toxins, which cleave epidermal desmogleins, leading to staphylococcal scalded skin syndrome (50, 51). However, the vast majority of $S$. aureus virulence factors have been investigated solely for their role in contributing to invasive disease and remain largely ignored from the perspective of asymptomatic colonization. Considering the evolutionary pressure on $S$. aureus for effective transmission and the relatively infrequent occurrence of invasive infections relative to the high prevalence of colonization, it is likely that many staphylococcal virulence factors are involved in establishing and maintaining the colonization state. Clumping factor B is a clear example of a $S$. aureus virulence factor with dual roles in both the pathogenesis of a systematic infection and colonization. In bloodstream infections, clumping factor B binds to the $\alpha$-chain of fibrinogen, promoting platelet aggregation, and staphylococcal attachment to damaged tissue in endocarditis (52, 53). Nevertheless, it is one of the few known critical determinants of nasal colonization and has been shown to facilitate adhesion to the keratinized epithelium through its interaction with cytokeratin 10 expressed on squamous cells $(18,54)$. Similarly, the secreted toxin $\alpha$-hemolysin has been shown to promote the cleavage of $\mathrm{E}$ cadherin in epithelia such as the lung and the skin in disease models (55). It seems very likely that the ability of $S$. aureus to modify host adherens junction biology may contribute to its ability to persist in the skin over time in a disease-free state. The 3D organotypic human epidermal tissue system will facilitate examination of the vast arsenal of $S$. aureus virulence factors with respect to the hypothesis that virulence factors may play unique roles in the biology of $S$. aureus colonization. One can assess the importance of a particular bacterial product through competition experiments where the same epidermal tissue is co-infected with wild type (WT) and isogenic mutant $S$. aureus strains. Each strain can be tracked via unique fluorophores, allowing observation of the fate of WT and mutant populations within the same stratified human tissue over time.

Examining the immune response to $S$. aureus cutaneous colonization and infections is an important potential application of a 3D human skin culture system. The bi-dimensional nature of traditional S. aureus infections of immune cell cultures in vitro 

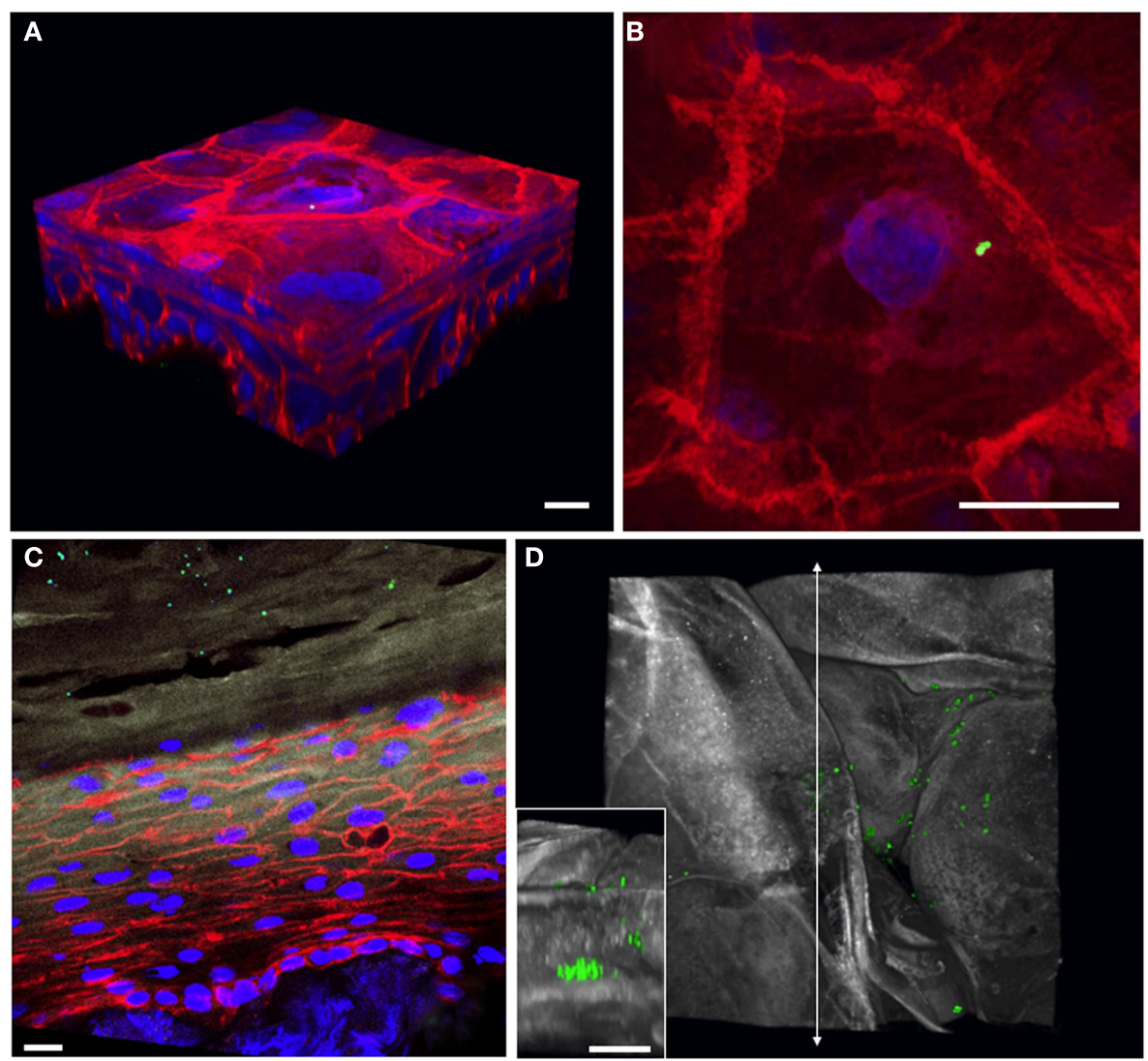

FIGURE 2 | Staphylococcus aureus adherence, growth, and localization can be observed within 3D organotypic human epidermal tissues. (A) 3D confocal microscopy reconstruction of an infected $(T=1 \mathrm{~h}) 5$-day-old $3 \mathrm{D}$ organotypic human epidermal tissue. S. aureus USA300 GFP-expressing bacteria (in green) are visible attached to the surface squames; filamentous actin is red, and nuclei are blue. Scale bar in all panels corresponds to $10 \mu \mathrm{m}$. (B) Top-down view of bacterial inoculum in (A), visualized immediately after infection. (C) Cross-sectional view of an 8-day-old 3D organotypic human epidermal tissue, infected with $S$. aureus USA300 GFP for 2 days. Bacteria (in green) are visible throughout the squames in the stratum corneum (loricrin in white). Filamentous actin is red and nuclei are in blue. (D) After 2 days of growth on the organotypic epidermal tissue, S. aureus USA300 GFP has started to form visible microcolonies within the squames in the stratum corneum in this top-down view (loricrin in white). Inset depicts a cross-sectional view located along the vertical line with arrows revealing a large staphylococcal microcolony. forces direct interactions between the bacteria and immune cells, which are not likely to represent the most physiologically relevant way in which an immune cell would encounter S. aureus. By incorporating relevant immune cell types such as Langerhans cells or neutrophils into the 3D skin culture system, future investigations could examine how $S$. aureus and immune cells interact with one another in stratified human epidermal tissue. Other investigators have successfully incorporated "Langerhans-like" immune cells into similar 3D dermatological skin cultures, although to our knowledge, these models have not yet been infected for use in microbiology studies (56-58). Additionally, treatment with antibodies directed against $S$. aureus or addition of recombinant cytokines in the basolateral media of the skin cultures could allow examining impact of immune response to $S$. aureus in the localized cutaneous setting. As more S. aureus vaccines move forward into clinical trials, it remains totally unknown how an efficacious antibody response to vaccination may impact $S$. aureus colonization burden (59). Studies using a 3D organotypic human epidermal tissue model will prove valuable in assessing how immunization against $S$. aureus might alter bacterial population behavior on the epidermis or protect against invasive epidermal infections.

In order to better understand staphylococcal colonization and the transition to invasive infections, we must study S. aureus in its natural habitat: the human stratified squamous keratinized epithelium. Our group and others have begun to use organotypic 3D human skin equivalent cultures to experimentally probe $S$. aureus colonization and infections $(36,60)$. It is our hope that moving toward more physiologically relevant model systems, which capture the complex biology of the skin, will allow us to better understand the critical interface between our most important tissue barrier and $S$. aureus.

\section{REFERENCES}

1. McCaig LF, McDonald LC, Mandal S, Jernigan DB. Staphylococcus aureusassociated skin and soft tissue infections in ambulatory care. Emerg Infect Dis (2006) 12:1715-23. doi:10.3201/eid1211.060190

2. Moran GJ, Amii RN, Abrahamian FM, Talan DAD. Methicillin-resistant Staphylococcus aureus in community-acquired skin infections. Emerg Infect Dis (2005) 11:928-30. doi:10.3201/eid1106.040641 
3. Eady EA, Cove JHJ. Staphylococcal resistance revisited: community-acquired methicillin resistant Staphylococcus aureus - an emerging problem for the management of skin and soft tissue infections. Curr Opin Infect Dis (2003) 16:103-24. doi:10.1097/00001432-200304000-00007

4. Grice EA, Segre JAJ. The skin microbiome. Nat Rev Microbiol (2011) 9:244-53. doi:10.1038/nrmicro2537

5. Kloos WE, Musselwhite MS. Distribution and persistence of Staphylococcus and Micrococcus species and other aerobic bacteria on human skin. Appl Environ Microbiol (1975) 30:381-95.

6. Kluytmans JJ, van Belkum AA, Verbrugh HH. Nasal carriage of Staphylococcus aureus: epidemiology, underlying mechanisms, and associated risks. Clin Microbiol Rev (1997) 10:505-20.

7. Eriksen NH, Espersen FF, Rosdahl VT, Jensen KK. Carriage of Staphylococcus aureus among 104 healthy persons during a 19-month period. Bull Entomol Res (1995) 115:51-60.

8. Noble WC, Valkenburg HA, Wolters CHC. Carriage of Staphylococcus aureus in random samples of a normal population. J Hyg (Lond) (1967) 65:567-73. doi:10.1017/S002217240004609X

9. Peacock SJ, Justice AA, Griffiths DD, de Silva GD, Kantzanou MN, Crook $\mathrm{DD}$, et al. Determinants of acquisition and carriage of Staphylococcus aureus in infancy. J Clin Microbiol (2003) 41:5718-25. doi:10.1128/JCM.41.12.57185725.2003

10. Schechter-Perkins EM, Mitchell PM, Murray KA, Rubin-Smith JE, Weir S, Gupta K. Prevalence and predictors of nasal and extranasal staphylococcal colonization in patients presenting to the emergency department. Ann Emerg Med (2011) 57:492-9. doi:10.1016/j.annemergmed.2010.11.024

11. Yang ES, Tan JJ, Eells SS, Rieg GG, Tagudar GG, Miller LGL. Body site colonization in patients with community-associated methicillin-resistant Staphylococcus aureus and other types of S. aureus skin infections. Clin Microbiol Infect (2010) 16:425-31. doi:10.1111/j.1469-0691.2009.02836.x

12. McKinnell JA, Huang SS, Eells SJ, Cui E. Quantifying the impact of extranasal testing of body sites for methicillin-resistant Staphylococcus aureus colonization at the time of hospital or intensive care unit admission. Infect Control Hosp Epidemiol (2013) 34(2):161-70. doi:10.1086/669095

13. Wertheim HF, Vos MC, Ott AA, van Belkum AA, Voss AA, Kluytmans JA, et al. Risk and outcome of nosocomial Staphylococcus aureus bacteraemia in nasal carriers versus non-carriers. Lancet (2004) 364:3-3. doi:10.1016/S0140-6736(04) 16897-9

14. Wertheim HF, Melles DC, Vos MC, van Leeuwen W, van Belkum A, Verbrugh HA, et al. The role of nasal carriage in Staphylococcus aureus infections. Lancet Infect Dis (2005) 5:751-62. doi:10.1016/S1473-3099(05)70295-4

15. Smyth DS, Kafer JM, Wasserman GA, Velickovic LL, Mathema BB, Holzman RS, et al. Nasal carriage as a source of Agr-defective Staphylococcus aureus bacteremia. JInfect Dis (2012) 206:1168-77. doi:10.1093/infdis/ jis 483

16. von Eiff CC, Becker KK, Machka KK, Stammer HH, Peters GG. Nasal carriage as a source of Staphylococcus aureus bacteremia. Study Group. N Engl J Med (2001) 344:11-6. doi:10.1056/NEJM200101043440102

17. Krishna S, Miller LS. Host-pathogen interactions between the skin and Staphylococcus aureus. Curr Opin Microbiol (2012) 15:28-35. doi:10.1016/j.mib.2011. 11.003

18. O’Brien LM, Walsh EJ, Massey RC, Peacock SJ, Foster TJT. Staphylococcus aureus clumping factor B (ClfB) promotes adherence to human type I cytokeratin 10: implications for nasal colonization. Cell Microbiol (2002) 4:759-70. doi:10.1046/j.1462-5822.2002.00231.x

19. Onunkwo CC, Hahn BL, Sohnle PG. Clearance of experimental cutaneous Staphylococcus aureus infections in mice. Arch Dermatol Res (2010) 302(5):375-82. doi:10.1007/s00403-010-1030-y

20. Kanzaki H, Morishita Y, Akiyama H, Arata J. Adhesion of Staphylococcus aureus to horny layer: role of fibrinogen. J Dermatol Sci (1996) 12:132-9. doi:10.1016/0923-1811(95)00472-6

21. Abe Y, Akiyama H, Arata J. Furuncle-like lesions in mouse experimental skin infections with Staphylococcus aureus. J Dermatol (1993) 20: 198-202.

22. Kugelberg E, Norström T, Petersen TK, Duvold T, Andersson DI, Hughes D. Establishment of a superficial skin infection model in mice by using Staphylococcus aureus and Streptococcus pyogenes. Antimicrob Agents Chemother (2005) 49:3435-41. doi:10.1128/AAC.49.8.3435-3441.2005
23. Prabhakara R, Foreman O, De Pascalis R, Lee GM, Plaut RD, Kim SY, et al. An epicutaneous model of community-acquired Staphylococcus aureus skin infections. Infect Immun (2013) 81(4):1306-15. doi:10.1128/IAI.01304- 12

24. Nippe N, Varga G, Holzinger D, Löffler B. Subcutaneous infection with S. aureus in mice reveals association of resistance with influx of neutrophils and Th2 response. J Invest Dermatol (2010) 131(1):125-32. doi:10.1038/jid.2010.282

25. Cho JS, Zussman J, Donegan NP, Ramos RI, Garcia NC, Uslan DZ, et al. Noninvasive in vivo imaging to evaluate immune responses and antimicrobial therapy against Staphylococcus aureus and USA300 MRSA skin infections. J Invest Dermatol (2011) 131:907-15. doi:10.1038/jid.2010.417

26. Kobayashi SD, Malachowa N, Whitney AR, Braughton KR, Gardner DJ, Long $\mathrm{D}$, et al. Comparative analysis of USA300 virulence determinants in a rabbit model of skin and soft tissue infection. J Infect Dis (2011) 204:937-41. doi:10.1093/infdis/jir441

27. Inoshima I, Inoshima N, Wilke GA, Powers ME, Frank KM, Wang Y, et al. A Staphylococcus aureus pore-forming toxin subverts the activity of ADAM10 to cause lethal infection in mice. Nat Med (2011) 17:1310-4. doi:10.1038/nm.2451

28. Ridky TW, Chow JM, Wong DJ, Khavari PA. Invasive three-dimensional organotypic neoplasia from multiple normal human epithelia. Nat Med (2010) 16:1450-5. doi:10.1038/nm.2265

29. Kretz MM, Siprashvili ZZ, Chu CC, Webster DE, Zehnder AA, Qu KK, et al. Control of somatic tissue differentiation by the long non-coding RNA TINCR. Nature (2013) 493:231-5. doi:10.1038/nature11661

30. Auxenfans C, Fradette J, Lequeux C, Germain L, Kinikoglu B, Bechetoille N, et al Evolution of three dimensional skin equivalent models reconstructed in vitro by tissue engineering. Eur J Dermatol (2009) 19:107-13. doi:10.1684/ejd.2008.0573

31. Groeber F, Holeiter M, Hampel M, Hinderer S, Schenke-Layland K. Skin tissue engineering - in vivo and in vitro applications. Adv Drug Deliv Rev (2011) 63:352-66. doi:10.1016/j.addr.2011.01.005

32. Lebonvallet N, Jeanmaire C, Danoux L, Sibille P, Pauly G, Misery L. The evolution and use of skin explants: potential and limitations for dermatological research. Eur J Dermatol (2010) 20:671-84. doi:10.1684/ejd.2010.1054

33. de Breij A, Haisma EM, Rietveld M, Ghalbzouri El A, van den Broek PJ, Dijkshoorn L, et al. Three-dimensional human skin equivalent as a tool to study Acinetobacter baumannii colonization. Antimicrob Agents Chemother (2012) 56:2459-64. doi:10.1128/AAC.05975-11

34. Hogk I, Rupp S, Burger-Kentischer A. 3D-tissue model for herpes simplex virus1 infections. Methods Mol Biol (2013) 1064:239-51. doi:10.1007/978-1-62703601-6_17

35. Schaller M, Schackert C, Korting HC, Januschke E, Hube B. Invasion of Candida albicans correlates with expression of secreted aspartic proteinases during experimental infection of human epidermis. J Invest Dermatol (2000) 114:712-7. doi:10.1046/j.1523-1747.2000.00935.x

36. Soong G, Chun J, Parker D, Prince A. Staphylococcus aureus activation of caspase $1 /$ calpain signaling mediates invasion through human keratinocytes. J Infect Dis (2012) 205:1571-9. doi:10.1093/infdis/jis244

37. Gangatirkar P, Paquet-Fifield S, Li A, Rossi R, Kaur P. Establishment of 3D organotypic cultures using human neonatal epidermal cells. Nat Protoc (2007) 2:178-86. doi:10.1038/nprot.2006.448

38. Stark H-J, Szabowski A, Fusenig NE, Maas-Szabowski N. Organotypic cocultures as skin equivalents: a complex and sophisticated in vitro system. Biol Proced Online (2004) 6:55-60. doi:10.1251/bpo72

39. Boelsma E, Verhoeven MC, Ponec M. Reconstruction of a human skin equivalent using a spontaneously transformed keratinocyte cell line (HaCaT). J Invest Dermatol (1999) 112:489-98. doi:10.1046/j.1523-1747.1999.00545.x

40. Maas-Szabowski N. Epidermal tissue regeneration and stromal interaction in HaCaT cells is initiated by TGF. J Cell Sci (2003) 116:2937-48. doi:10.1242/jcs. 00474

41. Schoop VM, Mirancea N, Fusenig NE. Epidermal organization and differentiation of HaCaT keratinocytes in organotypic coculture with human dermal fibroblasts. J Invest Dermatol (1999) 112:343-53. doi:10.1046/j.1523-1747.1999. 00524.x

42. Holland DB, Bojar RA, Farrar MD, Holland KT. Differential innate immune responses of a living skin equivalent model colonized by Staphylococcus epidermidis or Staphylococcus aureus. FEMS Microbiol Lett (2009) 290:149-55. doi:10.1111/j.1574-6968.2008.01402.x

43. Corriveau M-N, Zhang N, Holtappels G, Van Roy N, Bachert C. Detection of Staphylococcus aureus in nasal tissue with peptide nucleic acid-fluorescence 
in situ hybridization. Am J Rhinol Allergy (2009) 23:461-5. doi:10.2500/ajra. 2009.23.3367

44. Ohnemus U, Kohrmeyer K, Houdek P, Rohde H, Wladykowski E, Vidal S, et al. Regulation of epidermal tight-junctions (TJ) during infection with exfoliative toxin-negative Staphylococcus strains. J Invest Dermatol (2008) 128:906-16. doi:10.1038/sj.jid.5701070

45. McGrath JA, Uitto J. The filaggrin story: novel insights into skin-barrier function and disease. Trends Mol Med (2008) 14:8-8. doi:10.1016/j.molmed.2007.10.006

46. Hauser CC, Wuethrich BB, Matter LL, Wilhelm JA, Sonnabend WW, Schopfer KK. Staphylococcus aureus skin colonization in atopic dermatitis patients. Dermatologica (1985) 170:35-9. doi:10.1159/000249514

47. Leung DY, Bieber T. Atopic dermatitis. Lancet (2003) 361:10-10. doi:10.1016/ S0140-6736(03)12193-9

48. Leyden JJ, Marples RR, Kligman AMA. Staphylococcus aureus in the lesions of atopic dermatitis. Br J Dermatol (1974) 90:525-30. doi:10.1111/j.1365-2133. 1974.tb06447.x

49. Mildner M, Jin J, Eckhart L, Kezic S, Gruber F, Barresi C, et al. Knockdown of filaggrin impairs diffusion barrier function and increases UV sensitivity in a human skin model. J Invest Dermatol (2010) 130:2286-94. doi:10.1038/jid. 2010.115

50. Amagai MM, Stanley JRJ. Desmoglein as a target in skin disease and beyond. J Invest Dermatol (2012) 132:776-84. doi:10.1038/jid.2011.390

51. Bukowski MM, Wladyka BB, Dubin GG. Exfoliative toxins of Staphylococcus aureus. Toxins (Basel) (2010) 2:1148-65. doi:10.3390/toxins2051148

52. Ganesh VK, Barbu EM, Deivanayagam CC, Le BB, Anderson AS, Matsuka YV, et al. Structural and biochemical characterization of Staphylococcus aureus clumping factor B/ligand interactions. J Biol Chem (2011) 286:25963-72. doi:10.1074/jbc.M110.217414

53. Miajlovic HH, Loughman AA, Brennan MM, Cox DD, Foster TJT. Both complement- and fibrinogen-dependent mechanisms contribute to platelet aggregation mediated by Staphylococcus aureus clumping factor B. Infect Immun (2007) 75:3335-43. doi:10.1128/IAI.01993-06

54. Walsh EJ, O'Brien LM, Liang XX, Hook MM, Foster TJT. Clumping factor B, a fibrinogen-binding MSCRAMM (microbial surface components recognizing adhesive matrix molecules) adhesin of Staphylococcus aureus, also binds to the tail region of type I cytokeratin 10. J Biol Chem (2004) 279:50691-9. doi:10.1074/jbc.M408713200
55. Wilke GA, Wardenburg JB. Role of a disintegrin and metalloprotease 10 in Staphylococcus aureus alpha-hemolysin-mediated cellular injury. Proc Natl Acad Sci U S A (2010) 107:13473-8. doi:10.1073/pnas.1001815107

56. Ouwehand K, Spiekstra SW, Waaijman T, Scheper RJ, de Gruijl TD, Gibbs S. Technical advance: Langerhans cells derived from a human cell line in a fullthickness skin equivalent undergo allergen-induced maturation and migration. J Leukoc Biol (2011) 90:1027-33. doi:10.1189/jlb.0610374

57. Dezutter-Dambuyant C, Black A, Bechetoille N, Bouez C, Maréchal S, Auxenfans $\mathrm{C}$, et al. Evolutive skin reconstructions: from the dermal collagenglycosaminoglycan-chitosane substrate to an immunocompetent reconstructed skin. Biomed Mater Eng (2006) 16:S85-94.

58. Laubach V, Zöller N, Rossberg M, Görg K, Kippenberger S, Bereiter-Hahn J, et al. Integration of Langerhans-like cells into a human skin equivalent. Arch Dermatol Res (2010) 303:135-9. doi:10.1007/s00403-010-1092-x

59. van Belkum AA. Staphylococcal colonization and infection: homeostasis versus disbalance of human (innate) immunity and bacterial virulence. Curr Opin Infect Dis (2006) 19:339-44. doi:10.1097/01.qco.0000235159.40184.61

60. Quinn GA, Tarwater PM, Cole AM. Subversion of interleukin-1-mediated host defence by a nasal carrier strain of Staphylococcus aureus. Immunology (2009) 128:e222-9. doi:10.1111/j.1365-2567.2008.02952.x

Conflict of Interest Statement: Fabio Bagnoli and Guido Grandi are employees of Novartis Vaccines and Diagnostics.

Received: 07 November 2013; accepted: 23 January 2014; published online: 06 February 2014.

Citation: Popov L, Kovalski J, Grandi G, Bagnoli F and Amieva MR (2014) Threedimensional human skin models to understand Staphylococcus aureus skin colonization and infection. Front. Immunol. 5:41. doi: 10.3389/fimmu.2014.00041

This article was submitted to Microbial Immunology, a section of the journal Frontiers in Immunology.

Copyright $\odot 2014$ Popov, Kovalski, Grandi, Bagnoli and Amieva. This is an openaccess article distributed under the terms of the Creative Commons Attribution License (CC BY). The use, distribution or reproduction in other forums is permitted, provided the original author(s) or licensor are credited and that the original publication in this journal is cited, in accordance with accepted academic practice. No use, distribution or reproduction is permitted which does not comply with these terms. 